\title{
Fluid Structure Interaction of Submerged Metallic and Composite Plates Subjected to Low Velocity Impact Loading
}

\author{
P.R. Hampson ${ }^{\mathrm{a}}$, M. Moatamedi ${ }^{\mathrm{b}, *}$ \\ anstitute for Materials Research, University of Salford, Manchester, M5 4WT, UK \\ ${ }^{\mathrm{b}}$ School of Applied Sciences, Cranfield University, Cranfield, MK43 0AL, UK \\ * Corresponding author. Tel.; +44 (0) 123475 4034; fax; +44 (0) 1234751671 \\ E-mail address: m.moatamedi@ cranfield.ac.uk
}

\begin{abstract}
An instrumented low velocity impact rig has been used to acquire experimental data for impacts in air and underwater for both metallic and composite plates when subjected to a low velocity drop-weight impact with a $2 \mathrm{~kg}$ steel impactor. Initial impact studies were conducted in air and then repeated for submersed conditions underwater. Experimental results are compared for all tests with numerical solutions and are found to be in good agreement.
\end{abstract}

For underwater impact, the numerical model incorporates the use of a Eulerian formulation for the water with a coupled fluid-structure interaction algorithm. The effect of the water surrounding the target plates was found to reduce the peak accelerations and also reduce the overall impact duration when compared to the same impacts in air. X-Ray imagery of the composite plates also showed visibly reduced damage for the submersed test specimens.

This research provides data on the impact response of metallic and composite materials, and validates numerical methodologies for use in future work on fluidstructure interactions which show strong potential for relevant industrial applications.

KEY WORDS: Fluid-Structure Interaction (FSI); Finite element (FE); Low velocity impact; Metallic; Composite

\section{INTRODUCTION}

At the commencement of this research, a comprehensive literature review was conducted [1] from which it was evident that an important consideration when designing composite structures is their susceptibility to damage caused by impact loading. Even under relatively low velocity impact, composites are vulnerable to internal damage caused by transverse loads but unlike metallic structures material damage for composites can be hidden within the material and show no form of external damage. In some cases, barely visible impact damage (BVID) may occur which, even if detected by visual inspection would give no real indication to the severity of the internal material degradation.

Since many composites are being utilised in high performance applications, it is also important that the formation of damage under impact conditions is fully understood and by investigating the different damage mechanisms experienced by composite materials, improvements in the damage resistance characteristics of the composites 
can be made. Composites are also being widely implemented in underwater structures [2-3], and marine structures [4-9], thus making the Fluid-Structure Interaction (FSI) problem an important area of research.

This paper aims to establish an experimental and numerical methodology for investigating the impact response of metallic and composite materials for conditions of both in air and fully submerged underwater. X-Ray photography is also used to visualise the internal damage for the composite impact experiments.

\section{EXPERIMENTAL INVESTIGATION}

\subsection{Experimental Methodology}

The experimental investigation was conducted using a $2 \mathrm{~kg}$ drop-weight with a hemispherical impact tup from a drop height of $0.5 \mathrm{~m}$. Target plates for both the metallic and composite investigation were $200 \mathrm{x} 200 \mathrm{~mm}$ with an effective target size of $150 \times 150 \mathrm{~mm}$ once clamped into position on the impact rig.

For each of the different impact conditions, several impact studies were conducted with data collected at a rate of $40 \mathrm{kHz}$ for a duration of 1.5 seconds which was sufficient to capture the impact event. Test results were then averaged to provide a comparison for the numerical investigation.

The impact studies in air were conducted first for both material types before progressing onto the underwater investigation.

\subsection{Low Velocity Impact Rig}

For the experimental investigation performed in this study, a low velocity impact rig was built which incorporated an instrumented drop weight guided by a vertical tube. The low velocity experimental rig was set as shown schematically in Figure 1 and the impact rig specifications are shown in Table 1. 


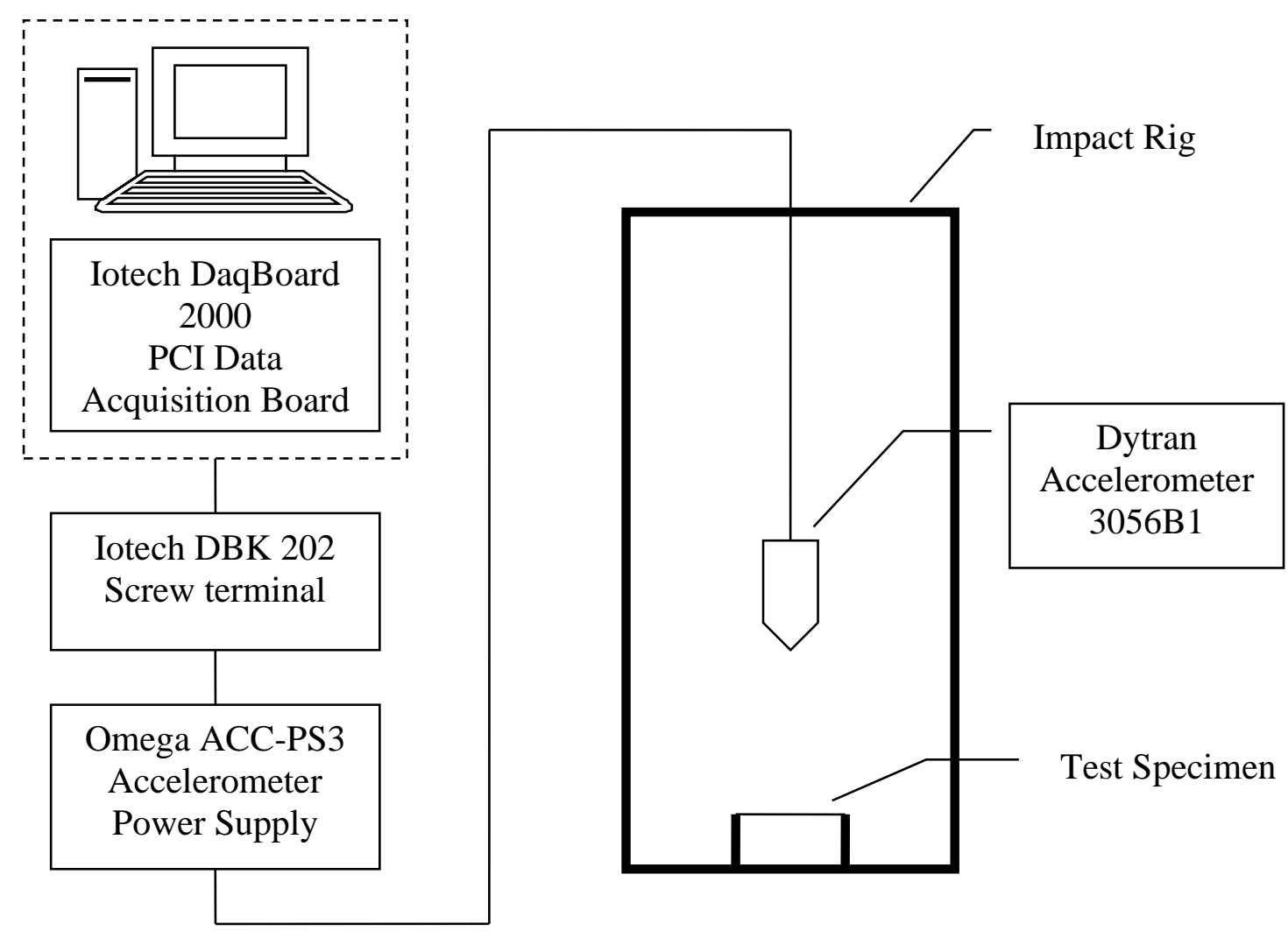

Figure 1. Schematic diagram of instrumented low velocity impact rig

\begin{tabular}{cc}
\hline Maximum drop height & $1.8 \mathrm{~m}$ \\
Fixed weight impactor & $2 \mathrm{~kg}$ \\
Maximum velocity & $6 \mathrm{~m} / \mathrm{s}$ \\
Maximum energy & $35 \mathrm{~J}$ \\
Effective target size & $150 \times 150 \mathrm{~mm}$ \\
Impact tip & Hemispherical \\
& $(25 \mathrm{~mm}$ diameter $)$ \\
\hline
\end{tabular}

Table 1. Low velocity impact rig specifications

An accelerometer was mounted on the top of the drop-weight impactor and a data resolution study was conducted to determine the optimum data sampling rate to ensure that peak outputs were captured. This was followed by initial impact tests on metallic and composite samples to confirm the impact rig was capable of collecting meaningful and repeatable data.

For all of experimental work conducted in this study, high speed videography was used to observe the impact dynamics, thus allowing a visual check to ensure no gross errors were introduced due to poor contact with the test plates or excessive vibration/deflection of the impact rig. 


\subsection{Modification of Impact Rig for Water Investigation}

Once the impact in air studies had been completed, the impact rig was modified for underwater impacts by adjusting the test sample clamping frame and placing it inside a Perspex trough which could be filled with water as shown in Figure 2.

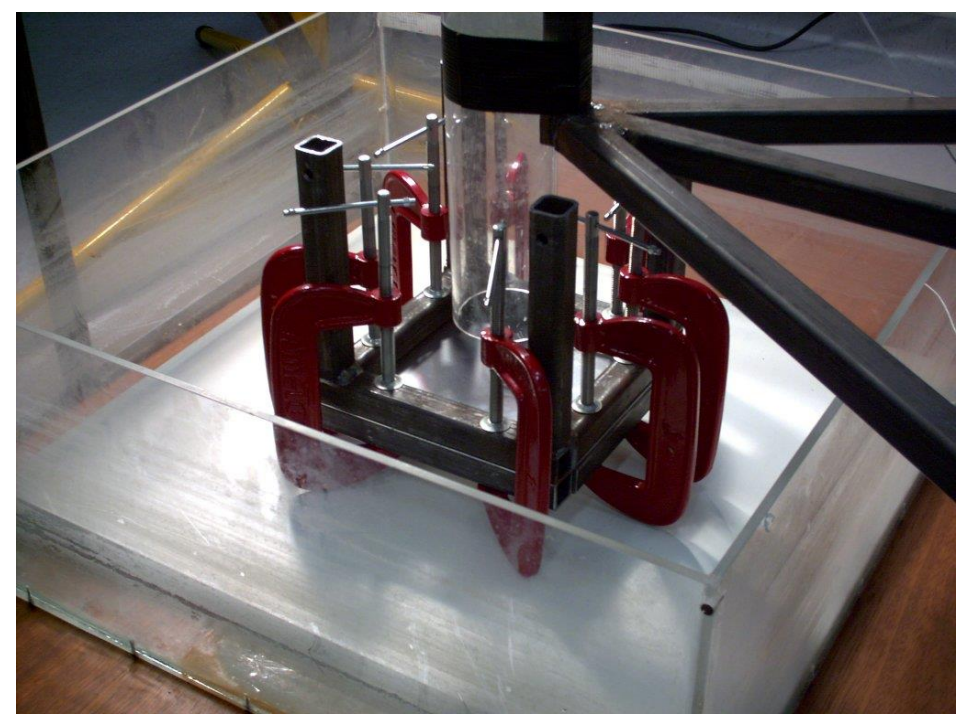

Figure 2. Modified impact rig for underwater impact studies

Since the clamping frame had been adjusted, it was necessary to conduct a 'dry run' to ensure that the modifications would not alter the experimental results. An impact with a metallic target was repeated so a comparison could be made between the results obtained for the original and modified configurations and it was seen that there had been a negligible effect, therefore when water was added to the trough, any subsequent changes to the impact response could be attributed to the presence of the water.

The trough was then filled with water and the depth of the specimen was placed as shown in Figure 3. When submerging the test sample, care was taken to ensure that all air trapped underneath the sample was expelled.

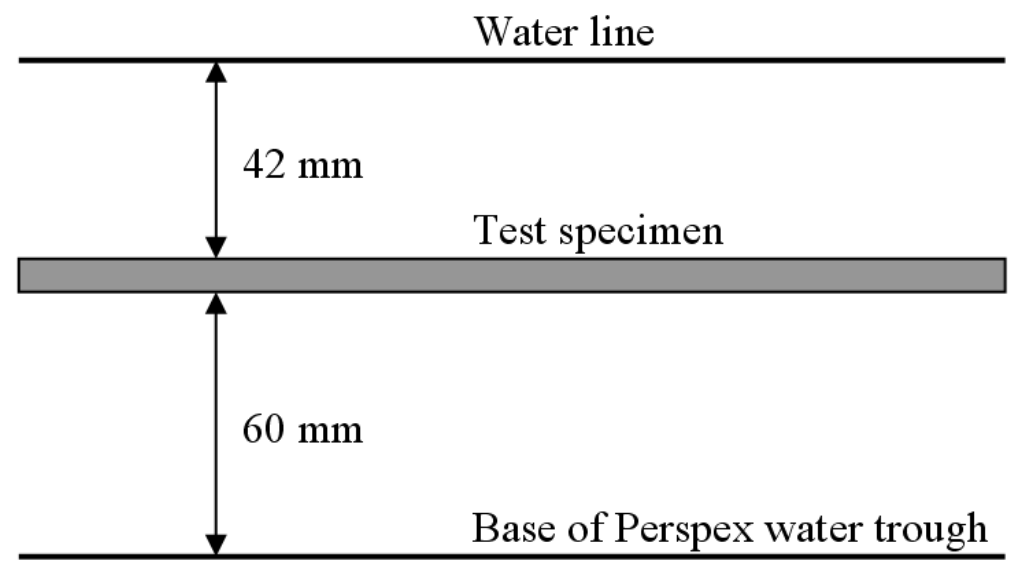

Figure 3. Depth of water above and below test specimen 


\subsection{Test Specimen Preparation}

The metallic investigation was conducted using 200 x $200 \mathrm{~mm}$ test specimens of unalloyed Aluminium 1050A with an average thickness of $1.43 \mathrm{~mm}$.

For the composite investigation, specimens were made from unidirectional carbon fibre reinforced plastic (CFRP) prepreg with 16 plys in the following lay-up sequence $[0 / 90 / 90 / 0]_{4}$. This balanced layup ensured that thermally induced bending and warping of the sample during curing and cooling was considerably reduced.

The layup was constructed inside a $200 \times 200 \mathrm{~mm}$ metal template and then placed into a heated press where it was then cured at a temperature of $180^{\circ} \mathrm{C} \pm 5^{\circ} \mathrm{C}$ with an applied pressure of $10 \mathrm{~kg} / \mathrm{cm}^{2}$ for a duration of 120 minutes. Several samples were made following this procedure and consecutively numbered for experimental identification purposes. The average cured laminate sample thickness was $1.92 \mathrm{~mm}$.

\section{NUMERICAL MODELLING}

\subsection{Methodology and Fluid-Structure Interaction (FSI)}

For some numerical problems, neither pure Lagrangian or Eulerian methodologies [10] are sufficient to model complexities such as large deformation dynamics, free surfaces, moving boundaries and interface contact problems.

In a pure Lagrangian formulation, the mesh moves with the material which makes tracking of interfaces and application of boundary conditions a simple task but does however lead to complications during high deformation dynamics where mesh entanglement and poor element conditioning can cause numerical solutions to fail.

For a pure Eulerian formulation, the mesh remains fixed while the material passes through it. By using this method the problems associated with Lagrangian mesh distortion can be avoided but it can be relatively difficult to track changes to interfaces and boundary conditions.

Since the Lagrangian method is particularly suited for solid materials, and Eulerian for fluids, it is possible to utilise the benefits of both of these methods by implementing a fluid-structure interaction algorithm. For this to be achieved, a penalty coupling method is established to permit the flow of fluid around a solid structure without the fluid leaking (penetrating) into the solid material [11-13].

The fluid structure coupling algorithms used to solve the impact problem have already been developed and is available in the literature [14-15].

\subsection{Numerical Software and Material Data}

For the numerical work conducted in this study, the finite element software ANSYS/LS-DYNA has been employed. This software provided ANSYS with an 
interface to the LS-DYNA explicit dynamics program which is suited for the solution of short duration dynamic problems.

The problem was first modelled using the ANSYS pre-processor, and then solved explicitly using LS-DYNA and once a solution had been obtained, the results were viewed using LS-PrePost. Since simulation times from initial studies had proven to be relatively short, it was deemed acceptable to model the whole problem as shown in Figure 4, rather than take advantage of symmetry conditions.

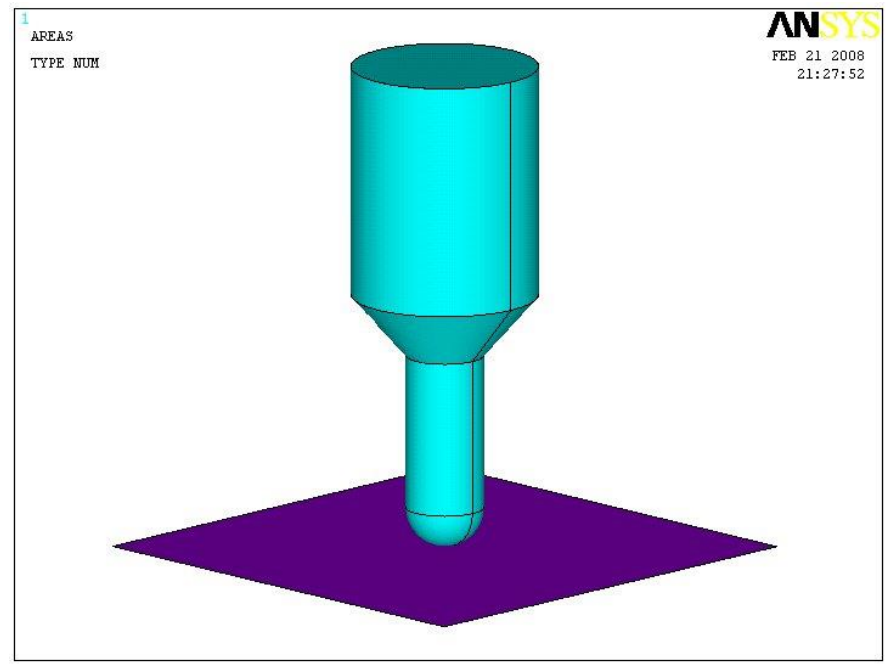

Figure 4. Impactor and target numerical model

The aluminium target plate was modelled using solid elements and assigned an elastic-plastic strain hardening material model (Plastic Kinematic) using the material properties listed in Table 2.

\begin{tabular}{cc}
\hline Material Name & Aluminium 1050A \\
Young's Modulus & $76 \mathrm{GPa}$ \\
Poisson's Ratio & 0.34 \\
Yield Strength & $0.34475 \mathrm{GPa}$ \\
Tangent Modulus & $0.6895 \mathrm{GPa}$ \\
Hardening Parameter & 0.2 \\
Density & $2720 \mathrm{~kg} / \mathrm{m}^{3}$ \\
Failure Strain & 0.2 \\
\hline
\end{tabular}

Table 2. Aluminium target material data

The composite plate was modelled with shell elements and assigned the following composite material properties:

$$
\begin{gathered}
\mathrm{E}_{1}=147.0 \mathrm{GPa} \quad \mathrm{E}_{2}=18.0 \mathrm{GPa} \quad \mathrm{G}_{12}=4.7 \mathrm{GPa} \\
v_{12}=0.3 \quad \rho=1580 \mathrm{~kg} / \mathrm{m}^{3}
\end{gathered}
$$

For all numerical studies, the mild steel drop-weight was modelled as a rigid model using solid elements and assigned an initial velocity of $3.13 \mathrm{~m} / \mathrm{s}$ at the point of contact with the plate. Material properties are given as:

$$
\mathrm{E}=200 \mathrm{GPa} \quad v=0.3 \quad \rho=7854 \mathrm{~kg} / \mathrm{m}^{3}
$$




\subsection{Fluid-Structure Interaction Numerical Modelling}

In order to simplify the modelling, the geometry of the impactor was replaced with a sphere and assigned the same material properties of steel, but with an adjusted density value to ensure the inertial effects of the impactor remained unchanged from the previous simulations.

To confirm that the new modelling method yielded the same results, a comparison was made for the aluminium impact in air, the results of which are shown in Figure 5 and are identical. This proves that the actual geometry of the impactor doesn't effect the simulation provided that the actual hemispherical contact part retains the correct radius and the density is adjusted.

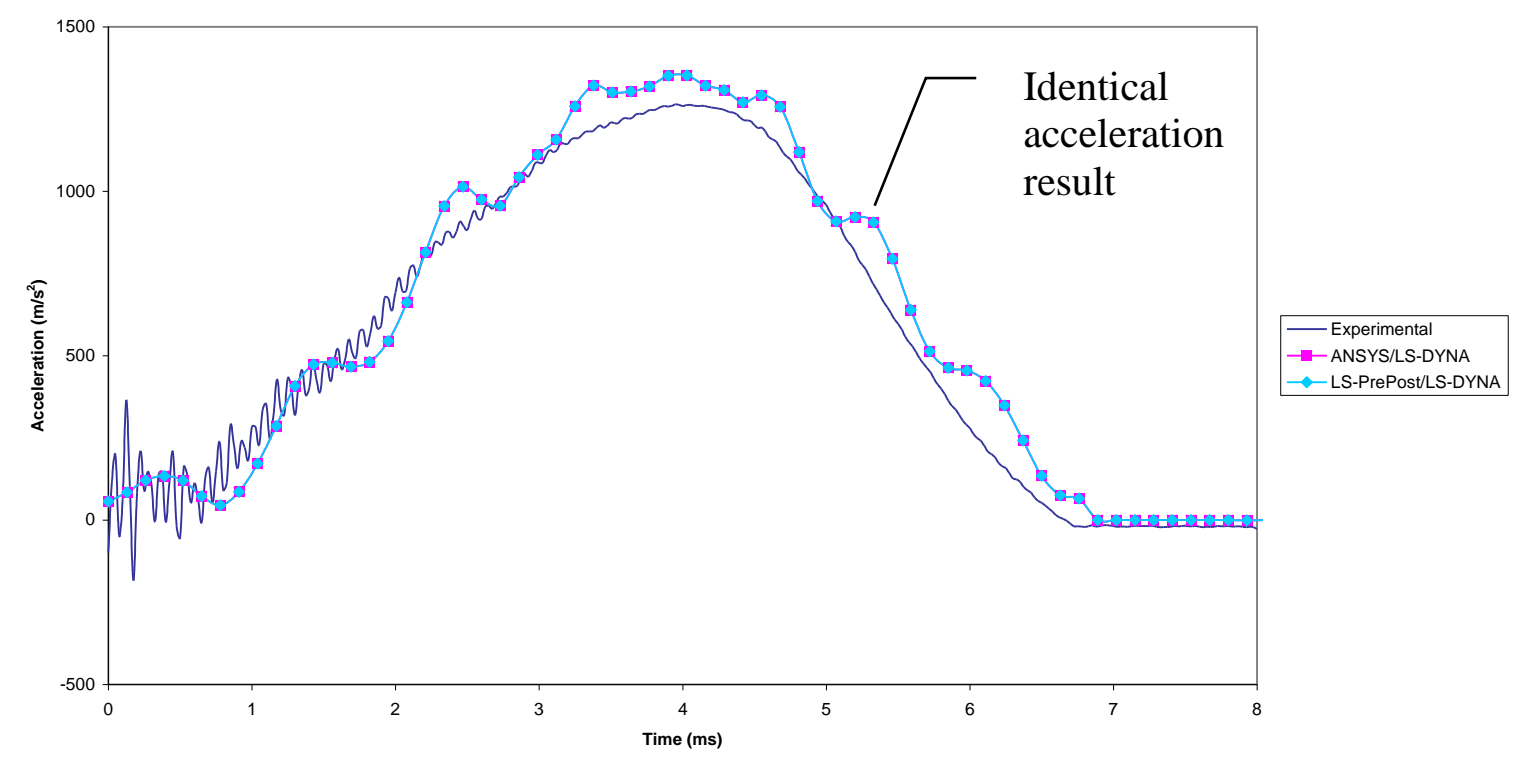

Figure 5. Comparison of numerical models created in ANSYS and LS-PrePost

An initial submerged model was created which enclosed the target plate with an arbitrary volume of water (Figure 6). To assess if the FSI formulations and modelling methods were being implemented successfully, a water depth of $30 \mathrm{~mm}$ was selected to permit a relatively rapid solution time, even though this did not represent the experimental conditions.

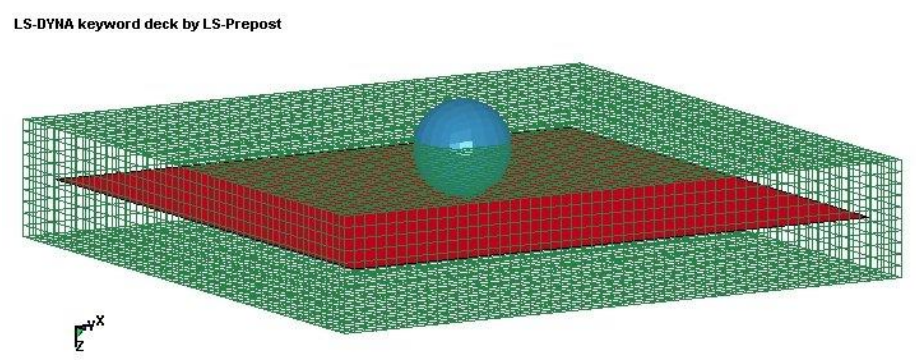

Figure 6. Impact problem surrounded by reduced water domain 
The ball impactor and target plate were modelled with Lagrangian method whilst the water was modelled using Eulerian method. A fluid-structure interaction algorithm was also established to couple the two modelling types.

The material data used to model the volume of water is shown in Table 3. These parameters were implemented using LS-DYNA's *MAT_NULL to define the density of the water, and *EOS_GRUNESIEN to define the equation-of-state for the pressurevolume relation in the water.

\begin{tabular}{ccc}
\hline Mass Density & $\rho$ & $998.21 \mathrm{~kg} / \mathrm{m}^{3}$ \\
Dynamic Viscosity Coefficient & $\mu$ & $0.001002 \mathrm{PaS}$ \\
Pressure Cut-off & $\mathrm{P}_{0}$ & -10 \\
Bulk Speed of Sound & $\mathrm{C}$ & $1647 \mathrm{~m} / \mathrm{s}$ \\
Gruneisen Parameter & $\mathrm{S} 1$ & 1.921 \\
Gruneisen Parameter & $\mathrm{S} 2$ & -0.096 \\
Gruneisen Parameter & $\mathrm{S} 3$ & 0 \\
Gruneisen Gamma & $\gamma_{0}$ & 0.35 \\
Internal Energy per Reference & $\mathrm{e}_{\text {ipvo }}$ & $289500 \mathrm{~N} / \mathrm{m}^{2}$ \\
Specific Volume & & \\
\hline
\end{tabular}

Table 3. Water parameters for Null and Gruneisen Equation of State material models

Coupling between the target plate and the water was achieved using the *CONSTRAINED_LAGRANGIAN_IN_SOLID fluid-structure interaction algorithm [16], where the MASTER part was defined as the water (fluid) and the SLAVE part as the target plate. Within this algorithm, it was also important to adjust several other parameters to control various simulation characteristics. The NQUAD option which determines the number of control points to detect penetration between the contact entities was assigned a value of 5 since this was found to be sufficient to prevent 'leakage' of the fluid part through the Lagrangian component. The CTYPE option which specifies the fluid-structure coupling method was assigned a value of 4 , thereby providing penalty coupling for shell and solid elements. DIREC which specifies the coupling direction was assigned a value of 1 to activate coupling in the normal direction for conditions of both tension and compression.

Since the earlier water model (Figure 6) had produced good results, it was then acceptable to remodel the problem with more elements to reflect the actual water depths as used in the experimental investigation (Figure 7).

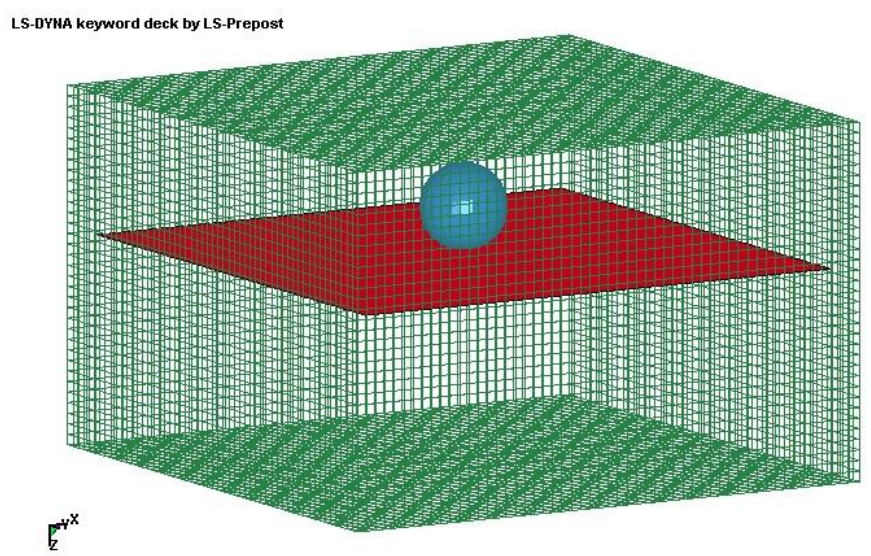

Figure 7. Impact problem surrounded by full water domain 
A sequence of water pressure results for the initial $450 \mu$ s of impact of the aluminium specimen is shown in Figure 8. It can be seen that the fluid-structure interaction is taking place since a pressure pulse wave is generated at the point of impact which then proceeds to move out towards the edges of the target plate. The acceleration response of the impactor was also observed to have been reduced when compared to the impact simulations in air.
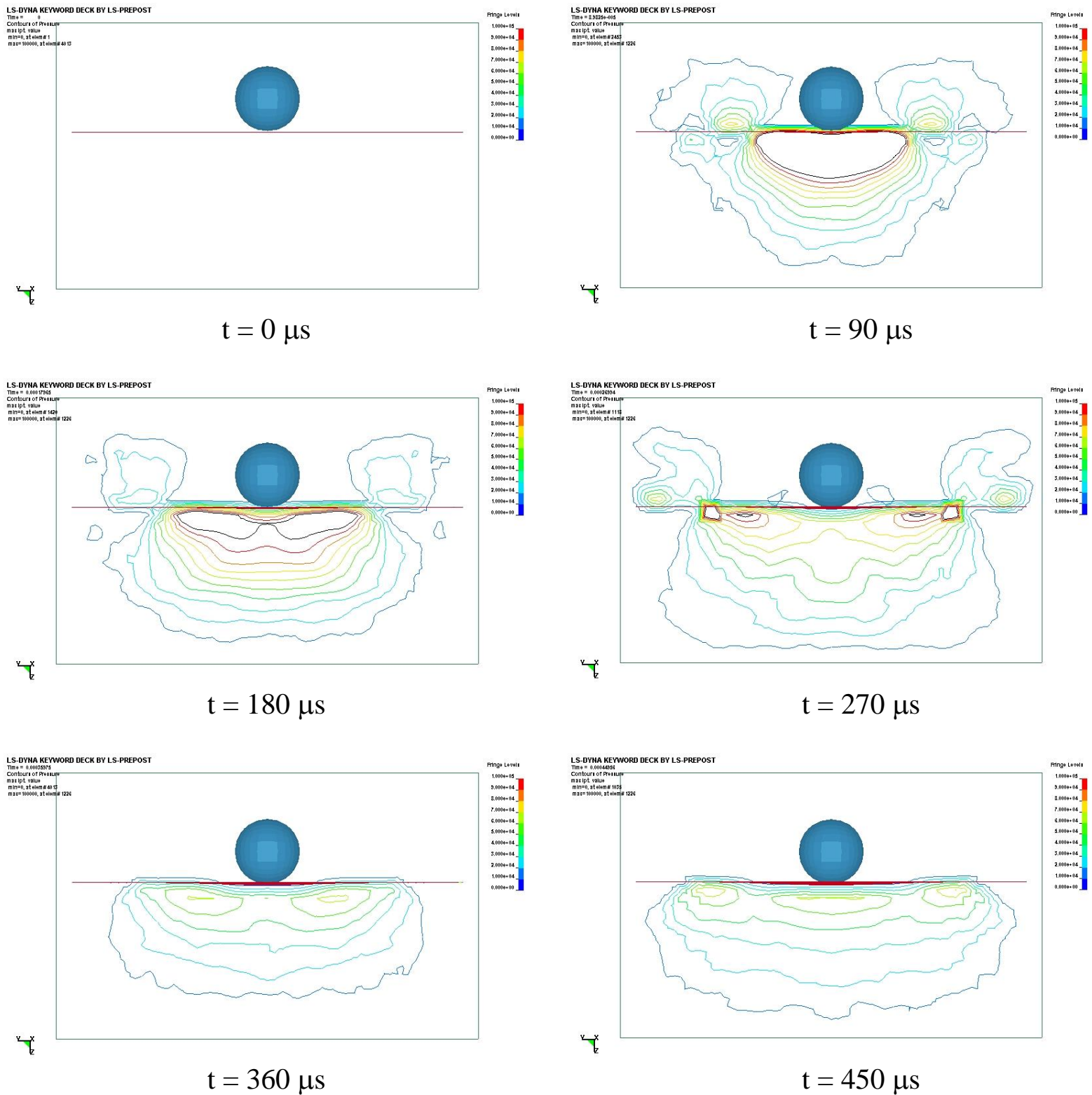

Figure 8. Typical series of aluminium underwater impact slides 
A similar sequence is shown in Figure 9 for the first $450 \mu$ s of impact for the composite test specimen.
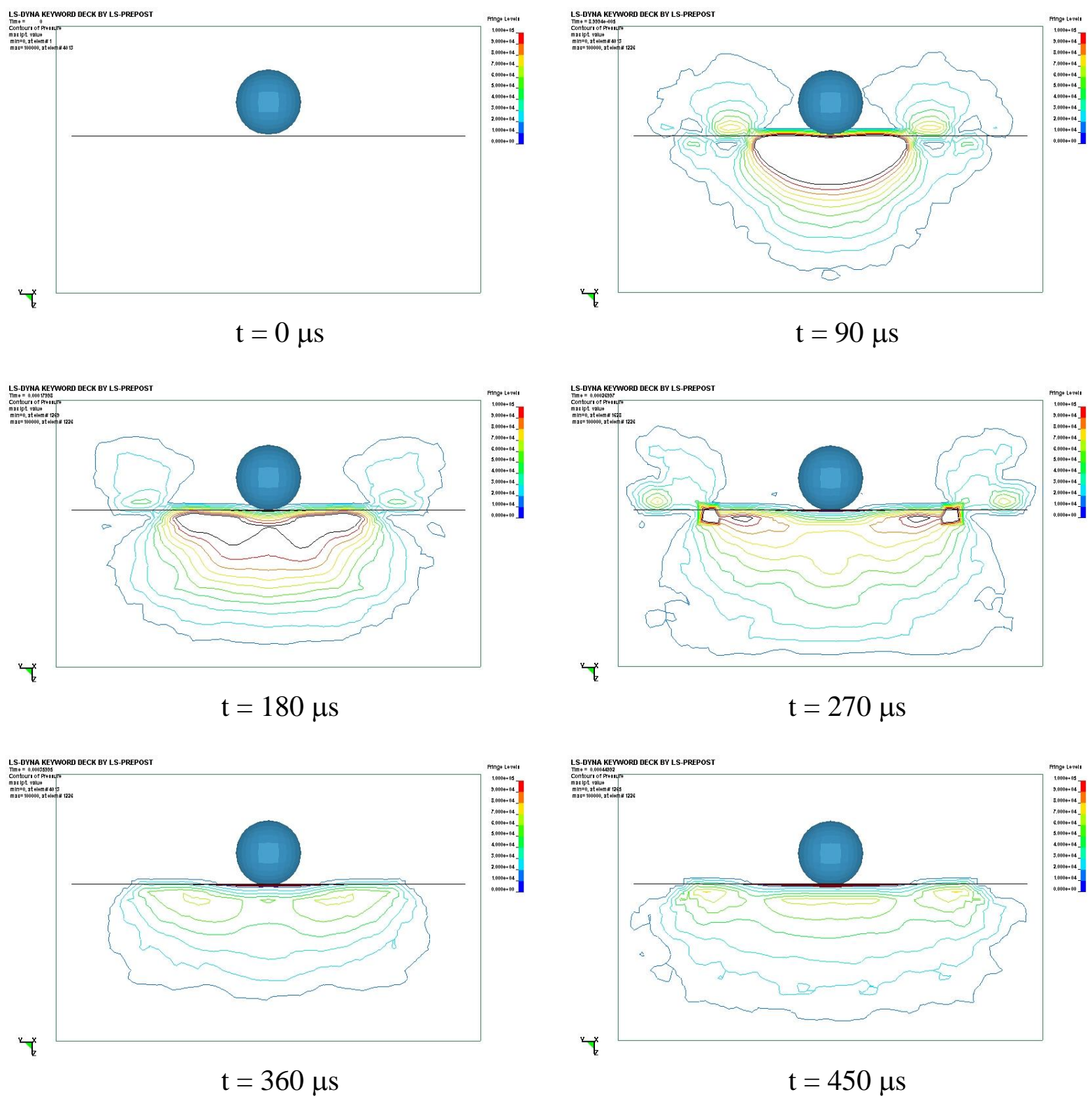

Figure 9. Typical series of composite underwater impact slides

\section{RESULTS AND DISCUSSION}

\subsection{Acceleration Experimental and Numerical Comparison}

Superimposed on the same graph in Figure 10, are the metallic target impact responses for experimental and numerical work for both impact in air and impact underwater. The graph permits easy comparison between the response behaviour of the material under the different conditions. It is interesting to note that the volume of water has effectively reduced the overall acceleration and impact duration. 


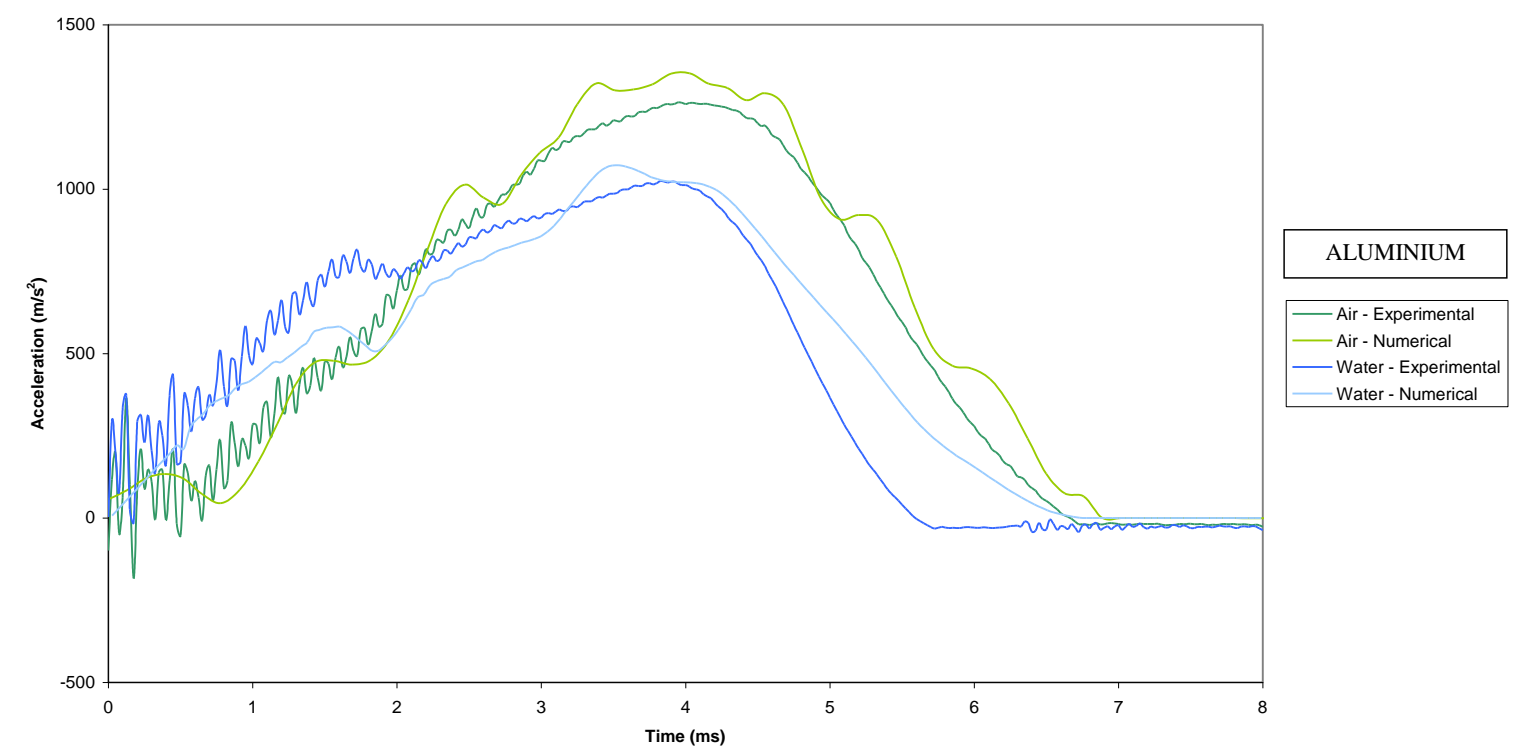

Figure 10. Comparison of experimental and numerical impact in air \& water (metallic)

For the metallic impact in air results, it can be seen that there is close agreement between the experimental and numerical impactor acceleration history. Both show a total impact duration of $6.8 \mathrm{~ms}$ with a peak acceleration of $1300 \mathrm{~m} / \mathrm{s}^{2}$ occurring at $4 \mathrm{~ms}$ into the impact.

For the comparison between the experimental and numerical impact acceleration histories for the Aluminium test sample in water it can be seen that there is reasonable agreement between the two traces even though the numerical impact duration is approximately $0.75 \mathrm{~ms}$ longer than the experimental. It is interesting to note that both traces show a slight dip in the acceleration at about $1.9 \mathrm{~ms}$ although a difference of $169 \mathrm{~m} / \mathrm{s}^{2}$ between the two traces is shown at this time. More crucially, the peak acceleration experienced under this impact condition is in very close agreement with a value of $1030 \mathrm{~m} / \mathrm{s}^{2}$ for the experiment and $1070 \mathrm{~m} / \mathrm{s}^{2}$ for the numerical simulation.

Figure 11 shows a similar graph but this time for the composite target specimen for the acceleration impact responses in air and underwater. As for the metallic target investigation, the same effects are noticeable for the overall acceleration and impact duration. 


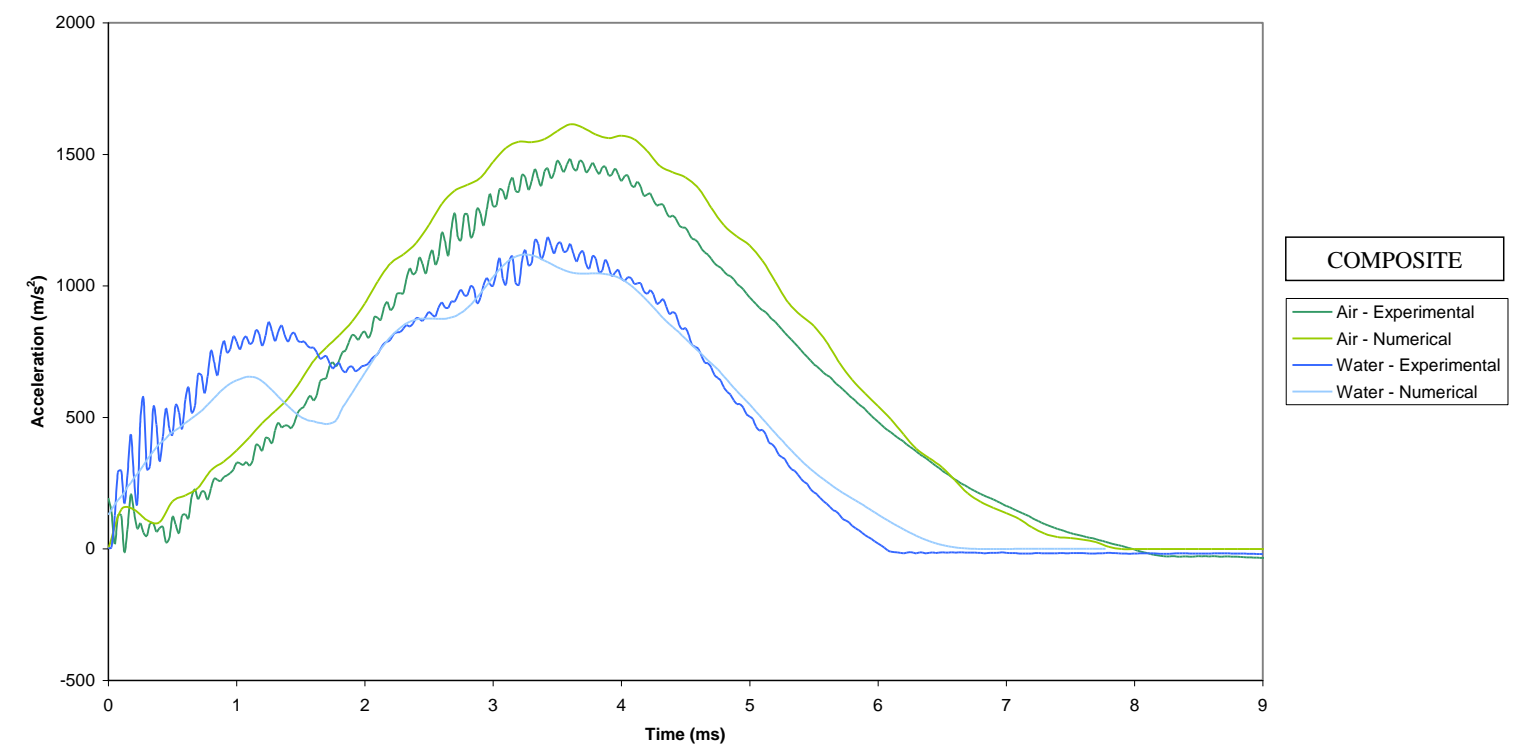

Figure 11. Comparison of experimental and numerical impact in air \& water (composite)

For the composite impact in air results, it can be seen that there is close agreement between the experimental and numerical impactor acceleration history with both showing a total impact duration of $8.2 \mathrm{~ms}$ with a peak acceleration of $1500 \mathrm{~m} / \mathrm{s}^{2}$ occurring at $3.7 \mathrm{~ms}$ into the impact.

For the composite impact in water results, there is reasonable agreement between the two traces and both show a slight dip in the acceleration at about $1.65 \mathrm{~ms}$ although a difference of $170 \mathrm{~m} / \mathrm{s}^{2}$ is shown at this time which is similar to the observations made for the metallic impact response. The peak acceleration experienced under this impact condition is in very close agreement with a value of $1160 \mathrm{~m} / \mathrm{s}^{2}$ for the experiment and $1120 \mathrm{~m} / \mathrm{s}^{2}$ for the numerical simulation.

For all of the impact comparisons, any slight discrepancies can be attributed to the assumption of a negligible frictional loss to the drop-weight as it contacts the guiding tube prior to impact, and for the numerical study it was assumed that all potential energy for the impactor prior to release would be converted into kinetic energy. The numerical model also assumes impact at the exact centre of the target plate which experimentally was difficult to achieve with the drop-weight impact rig where usually impact occurred within approximately a $2 \mathrm{~cm}$ diameter of the centre.

\subsection{Composite Material Internal Damage}

In Figure 12 are typical X-Ray comparisons for the $[0 / 90 / 90 / 0]_{4}$ unidirectional composite internal damage for the impact study in air and underwater. 


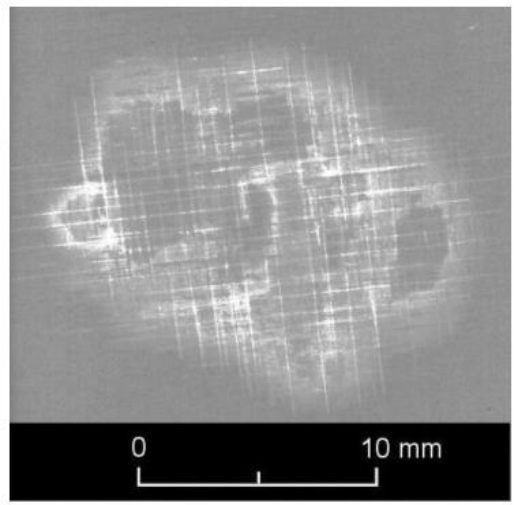

(a)

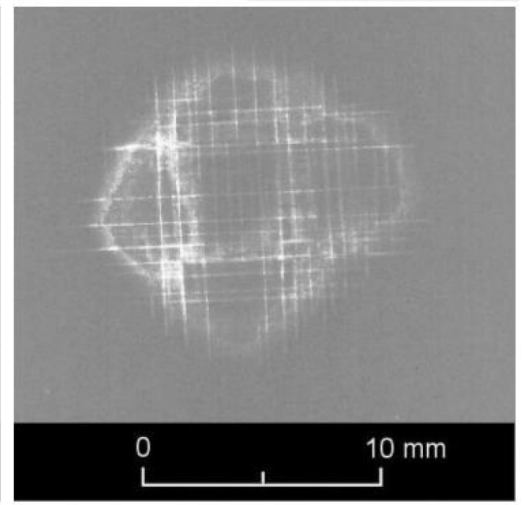

(b)

Figure 12. X-Ray comparison of $[0 / 90 / 90 / 0]_{4}$ unidirectional composite internal damage for (a) impact in air and (b) impact underwater

From the X-Ray results, it is clear to see that the internal damage of the composite material has been considerably reduced due to the presence of the surrounding water. It is also worthy to comment that non of the composite test specimens displayed any obvious external signs of damage under the impact conditions selected for this research, thus demonstrating the importance of non-destructive testing methods to assess the overall impact damage.

\section{CONCLUSION}

Undetected material failures in composite materials can greatly reduce the strength of the component which can occur quite easily during production, operation, and maintenance procedures, thus making composite behaviour a strong research topic with many areas still to be explored.

For this paper, an instrumented low velocity impact rig was used to acquire experimental data on the impact response of metallic and composite test specimens when subjected to impact in air and underwater. Comparisons were then made between the impact in air and impact underwater investigations to determine the effects of water on the target's ability to absorb the impact from which it was shown that the overall peak accelerations and impact durations were reduced.

For numerical comparison with experimental studies, the modelling of underwater impact incorporated the use of a Eulerian formulation and coupled fluid-structure interaction which was shown to predict with good accuracy the impact response of the underwater impact, therefore demonstrating their usefulness as a design tool for new structures.

X-Ray photography was also used to investigate the internal damage for the composite impact experiments from which it was shown the damage had been considerably reduced for specimens impacted underwater.

This research has provided data on the impact response of composites and validated numerical methodologies essential for use in future work on fluid-structure interactions and has shown there is a strong potential for underwater structures to be 
optimised since the peak accelerations they experience during impact is less than that for the same situation in air.

As computing technology rapidly improves, it will be possible to apply the numerical mythologies of fully coupled numerical modelling to more complex structures, therefore allowing greater understanding of fluid-structure interaction and it's applications to design optimisation of structures when submerged underwater or to impact upon water for the case of crashworthiness of structures such as aircraft.

Further applications of the fluid-structure interaction methodology could also be explored; especially with regard to transient dynamic underwater impacts and explosions. Particular attention could be placed on the modelling of blast loading scenarios for underwater explosions next to composite pipelines and the hulls of military ships.

\section{REFERENCES}

1 Hampson PR, Moatamedi M. A review of composite structures subjected to dynamic loading. International Journal of Crashworthiness 2007; 12(4):411428.

2. Sen R, Mullins G. Application of FRP composites for underwater piles repair. Composites Part B: Engineering 2007; 38(5-6):751-758.

3. Seica, MV, Packer JA. FRP materials for the rehabilitation of tubular steel structures for underwater applications. Composite Structures 2007; 80(3):440450.

4. Dyka CT, Badaliance R. Damage in marine composites caused by shock loading. Composites Science and Technology 1997; 58(9):1433-1442.

5. Hall DJ. Examination of the effects of underwater blasts on sandwich composite structures. Composite Structures 1989; 11(2):101-120.

6. McCoy RW, Sun CT. Fluid-structure interaction analysis of a thick-section composite cylinder subjected to underwater blast loading. Composite Structures 1997; 37(1):45-55.

7. Batra RC, Hassan NM. Response of fiber reinforced composites to underwater explosive loads. Composites Part B: Engineering 2007; 38(4):448-468.

8. Gong SW, Lam KY. Transient response of stiffened composite submersible hull subjected to underwater explosive shock. Composite Structures 1998; 41(1):27-37.

9. Gong SW, Lam KY. Transient response of floating composite ship section subjected to underwater shock. Composite Structures 1999; 46(1):65-71.

10. Benson DJ. Computational methods in Lagrangian and Eulerian hydrocodes. Computer Methods in Applied Mechanics and Engineering 1992; 99:235-394.

11. Aquelet N, Seddon C, Souli M, Moatamedi M. Initialisation of volume fraction in fluid/structure interaction problem. International Journal of Crashworthiness 2005; 10(3):237-247.

12. Aquelet N, Souli M, Olovsson L. Euler-Lagrange coupling with damping effects: Application to slamming problems. Computer Methods in Applied Mechanics and Engineering 2006; 195(1-3):110-132. 
13. Souli M, Ouahsine A, Lewin L. ALE formulation for fluid-structure interaction problems. Computer Methods in Applied Mechanics and Engineering 2000; 190(5-7):659-675.

14. Alia, A; Souli, M. High explosive simulation using multi-material formulations Applied Thermal Engineering 2006; 26 (10): 1032-1042

15. Longatte, E; Bendjeddou, Z; Souli, M. Application of Arbitrary Lagrange Euler formulations to flow-induced vibration problems. Journal of Pressure Vessel Technology - Transaction of the ASME 2003; 125 (4): 411-417

16. Hallquist JO. LS-Dyna Keyword Users Manual Volume 1 - Version 971. Livermore Software Technology Corporation, CA USA 2007. 